\title{
Media and the Medico-legal Expert
}

\author{
Ariyarathne $\mathrm{D}^{1}$, Hulathduwa SR ${ }^{1}$
}

\begin{abstract}
The rate and the diversity of crime have been increasing in Sri Lanka over the past few decades. A Judicial Medical Officer (JMO) plays a pivotal role in the criminal investigative process. JMOs also frequently involve with civil cases of public interest. The media tend to report on any matter either civil or criminal, in an elaborate and overemphasized manner to draw the public attention. In this context, a loquacious JMO would be a much preferred target by the media. Sociologists and criminal psychologists widely discuss the short-term and long-term positive and negative impacts of crime-reporting by the media upon the society. The media, criminal investigators (including the JMO), the suspects and the society are the four corner-stones of this dialogue with their own rights, ethics and legal obligations. For example, today's society expects to be swiftly updated with accurate and comprehensive information by different modalities of media under the principles of "public interest" and "right to know". The media has its own rights to gather information. The JMO should thoroughly understand the obligations, rights and limitations of the media and should try his best to maintain a fine balance with the "invasion" of media so as to prevent any injustice to his own reputation and to the interests of the victim, suspect, the public as well as the criminal justice system of the country. The JMO is principally accountable to the investigative authorities or to the courts. He is not a public figure or a celebrity to be highlighted while performing his lawful duties. It is timely that the medico-legal experts in Sri Lanka create a dialogue as to how they should interact with the intrusions of the media.
\end{abstract}

Key words: media, right to know, public interest, rights of JMO

\section{Full paper}

\section{Introduction}

The medico-legal expert in Sri Lanka is vested with a wide range of duties with both civil and criminal issues during his day-to-day practice of clinical forensic medicine and forensic pathology. The crime rate is high in Sri Lanka. ${ }^{[1]}$ This leads to an increased work load for the JMO. A dramatic increase of crime-related news both on the printed media as well as on the electronic media (including radio, TV and

${ }^{1}$ Senior Lecturer, Department of Forensic Medicine, Faculty of Medical Sciences, University of Sri Jayewardenepura, Sri Lanka

Corresponding author: Ariyarathne D. email:
weerawickramers@hotmail.com

DOI: http://doi.org/10.4038/mljsl.v4i2.7341 other forms of social media) has been noticed over the past two decades. This may either be due to an actual increase in the crime rate or due to a moreaggressiveform of crime-reporting. Few years ago certain television channels included sensitive issues of localexistence of crime in a given society.

Some consider it as an inevitable part of the society. They discuss about the stereotypy of crime though the person, place and time may differ from incidence to incidence. It is the common understanding that the media attempts to make crime-related news more elaborated and exaggerated by utilizing technology, sentimental language as well as retrievable evidencesuch as photos, videos, sounds and even voice-cuts. 
The JMO could easily get entangled in to these scenarios than any other medical specialist which could raise moral, ethical or even legal dilemmas as to the appropriateness of his conduct.

\section{Objectives}

The main objective of this concept paper is to develop a dialogue and lay a platform of discussion among the members of the medico-legal fraternity as to how the interaction between the JMO and the media should be. At the same time the authors wish to highlight the effects of some conflicting concepts such as "right to know" and "public interest" which often clash with the interests of the deceased or the patient.

\section{Discussion}

The word "Media" means collective communication outlets or tools used to store and deliver information or data. It could simply be the "communication media" such as the language or songs people use to express their ideas with each other or the specialized "mass media communication businesses" including but not limited to the print media and the press, photography, advertising, cinema, broadcasting (radio and television) and publishing". [2]

We live in the communication era which is characterized by the free and wide availability of different modalities of media across all strata of the society throughout the globe. The media plays a very strong and outstanding role in the society. The inherent duties of the media are to keep the public informed, educated and entertained. ${ }^{[3]}$ This helps the people to be kept abreast with the recent advances in the world, current trends in politics, economy or fine arts and enjoy the life with more alertness and awareness. As media reaches unimaginable numbers of individuals with short time, it has an enormous inherent capacity to build and alter the public opinion affecting the politics, economy or culture of a given society. This inherent capacity of media could be utilized both for purposeful agendas as well as to achieve destructive goals. The media has its own right for free communication. Yet, could this be utilized in a judgmental passion to arrive at conclusions in crucial matters?

Around the world, media ethics are well published (though not well established) which also apply to the paparazzi as well though an ethical debate or a dilemma exists especially when the role of the paparazzi is concerned. The JMO is not a public figure or a celebrity like a politician or a film star. He is only a public servant who carries out his designated duties within legal boundaries. The facts, observations and opinions he gathers during his duty essentially bear a legal value. When the media hunts for crime-related news, the JMO inevitably becomes a part and parcel of the story if not the main role.

Cana JMO reveal findings he gathered during his investigation directly to the media? The authors give a negative response to this question. The authors believe that the majority opinion would also be the same. It is prudent for the JMO to confine himself to divulging information only to the legal or investigative authorities. When the matter comes up in the open courts, it is common knowledge that such information is available to any party including the media. In exceptional cases, the media could be re-directed by the JMO to gather limited information from other sources such as the administrative head of the hospital or from the media-spokesman of the police department thus evading the difficult situation of being directly confronted by the media.

The society by large, has its own rights. The "public interest" and the "right to know" are two such concepts which might run in to direct conflict with the JMOs intention of not divulging the information he gathers during his official duty. The "right to know" the comprehensive and accurate factual details of the events occurring around one's social, economic, political and cultural environment is considered as a fundamental civil and political right. It is also an accepted norm that the "public interest" should be entertained at all times by the media. ${ }^{[4]}$ The concept of public interest could be extended to cover political, economic, health-related, environmental or criminal issues in the country.

These two concepts are widely abused by the media throughout the world to achieve their cheap economic agendas. Public interest should not be a justifiable excuse to broadcast names and other details of identity such as the place and time of certain important events and furthermore to explain the fine details of the exact modus operandi of the sensational crimes with the cheap agenda of quenching the natural thirst of the common public to know the "gossip". Socialpsychologists have identified that emotional, unusual, thrilling or spectacular incidents have a higher "newsworthy" value even over significant health warning with crippling outcomes. Consequently, to keep the attention of the audience, media may overutilize sensitive news. This phenomenon is termed "utilization of psychological buttons". ${ }^{[5]}$ According to Gans (1980); Graber, D. (1980); Chermak. (1995) 
news about deviance, crime and disaster are particularly effective in utilization of psychological buttons. Though the media is generally criticized for focusing mostly on bad news; the counter argument is that the general public pays more attention to bad stories with anger, revenge and grief than neutral or good news. ${ }^{[5,6,7]}$

Since people tend to rely on the news published by the media, there is an extensive power to convey any message globally in a matter of seconds. The "cultural selection theory" is in favour with this ideology. It is a well-known fact that media has a huge impact upon societies in subconsciously directing them towards the ways they are supposed to think, talk or behave. In other words, the way people act and react is greatly influenced by the media.

Do the media have a right to show or spread bad news or crime-related news within the society? Do the individuals of a community be benefitted in any way by being aware of the bad things or crimes happening around them? The positive psychological explanation for this is based on the concept of "community feeling" which is defined as "feeling, which encompasses the individual's awareness of belonging in the human community and the cosmos of which it is a part and an understanding of his or her responsibility for the way the life of the community is being shaped by his or her actions. It is a fundamental sense of being one amongst the others as a fellow being ". ${ }^{[8,9]}$

Not uncommonly, the media tend to violate their professional ethics by surpassing their limitations when reporting on crime-related news exercising their right explained in the previous paragraph. In addition to reporting the incidence and giving factual accounts, they tend to interpret the findings within their own limits of understanding and in the most plausible way or in the way the society would most like to hear. These include the opinions of the eye-witnesses, selfmade or "hired" experts and perhaps the voice-cuts of involved parties including the investigative authorities purposely edited to match the expectations of the media. Different types of evidence including physical, circumstantial, biological or direct are important tools in the criminal justice system. Furthermore, lay and expert witnesses and members of the jury too play an important role in arriving at a conclusion beyond reasonable doubt in the adversarial system. In this situation, pre-conceived ideas, mere assumptions and opinions expressed by the media even prior to the conclusion of the case, will have a drastic negative effect upon the criminal justice system. When the verdict arrived by the court of law differs from the public opinion created by the media, this will invariably create mistrust among the public towards the legal system. The JMO provides only a part of the scientific evidence in a criminal case. In the overall big picture of the crime, his contribution towards execution of justice may perhaps be trivial. Pre-trial information given by the same JMO involved with the case or any other JMO (as has happened in several occasions in the recent past) may negatively affect the case to be heard. The defense can formulate his defenses more strenuously. Certain physical evidence will be surreptitiously destroyed or altered by the interested parties. The prematurely expressed opinions could be challenged easily and if the same opinion is changed later that will have a negative impact upon the integrity of the JMO concerned in particular as well as on the profession in common.

The JMO's significance may be highlighted when he is involved with a high profile case. As a group of prudent medical professionals, we should have a clear insight of the common human weakness in want of undue recognition and respect. It is the authors' personal view that it is highly unethical to take photographs or video-record the JMO by paparazzi without the prior permission of the same. According to the Universal Declaration of Human Rights-1948, the right to privacy is explicitly stated under Article 12 as: "No one shall be subjected to arbitrary interference with his privacy, family, home or correspondence, nor to attacks upon his honor and reputation. Everyone has the right to the protection of the law against such interference or attacks. "Accordingly, if the media dare to interfere with the official duties of the JMO in an overtly disturbing manner (as video recording a process of exhumation from above) the JMO should not hesitate to inform the magistrate of the jurisdiction to take necessary preventive measures.

Does the JMO possess a right to decline him being shown on the media? We believe so. It will be one's discretion to appear or not to appear on media including newspapers and TV. If the JMO declines, we believe that the media has a moral and ethical obligation to respect that wish. The JMO may believe that he is more comfortable when unrecognized by the public especially when involved with a high profile case considering the political background of the country. Yet, this right is not absolute. It is legal to take photographs of a public place or an event by the media. ${ }^{[8]}$ Even when it is not in contrary with the existing law, we believe that the media should respect the personal right of the JMO to remain behind the screens. The practical application of this is highly 
questionable as the media rights and freedom are highly respected and recognized by the present day society more than ever. ${ }^{[11]}$

Crime scenes are often trespassed by the media. When it hinders the investigative process, the police can prevent the media men from entering the scene. Without entering the scene, they could try taking distant photographs and video-records with the hightech equipment they possess. The appropriateness of this move is highly questionable. There are a number of other scenes other than actual "crime scenes" where the media would love to invade. Train accidents, motor traffic accidents, different forms of suicides, decomposed bodies of the people who had died due to natural illnesses, infant deaths, deaths due to natural disasters etc. are just some examples. In most of these circumstances, the dead body or the bodies are not in the best shape to preserve the human dignity. We believe that in those circumstances, the JMO owes a humanitarian obligation to the deceased and his family members to politely remind the media of the inappropriateness of taking objectionable photographs insulting human dignity to be exposed publically. This is an instance where the so called "public interest" clashes with the "right to privacy". In most of the occasions it is quite dubious as to what type of public interest is fulfilled by displaying disfigured, dismembered and mutilated human bodies in mass media. This situation is worsened when even the members of the general public tend to take video clips and photographs from smart phones and up-load the same on the social media networks such as YouTube. One can experience the gravity of this situation if logged on to YouTube to see the number of local video clips with extremely disturbing and psychologically traumatizing scenarios like falling off heights, being run down by the train with complete trans section of lower limbs, suicidal hangings and so on. The danger of this situation is that once such information is released, they are open to the entire world and anybody could utilize such information anywhere for anything at any time.

In contrary to what has been so far discussed, there are also numerous local examples where the media had acted as an eye-opener of the criminal justice system to initiate necessary actions. The death of a five-year old girl, Seya Sadewmi which happened in Sri Lanka at Kotadeniyawa is one such note-worthy instance. $^{[12,13]}$

Another issue worthy of discussion is the contribution of JMOs in certain television programmes based on crimes. Crime scene investigation (CSI) programmes are popular even in the western part of the world such as CSI New York, CSI Miami and Prison Break. Similar programmes developed locally have been on the show in certain TV channels few years ago and it is a known fact that provision of background information and guidance as well as appearing on the screen to narrate certain information were done by certain individuals in the field of medico-legal practice. The contribution of such programmes towards prevention of crime in the society is debatable. The deterrent effect is questionable. Instead, one might argue that such programmes would contribute in providing unsolicited information to the criminals regarding crime investigation which will better equip them with ways and means of doing offenses under the investigator's nose without being noticed. ${ }^{[14,15]}$ The same is true for the elaborate newspaper articles explaining the explicit details of modus operandi of crimes and their investigations.

\section{Conclusions}

In conclusion, the authors wish to highlight the timely need to take necessary steps by the different stakeholders to devise acceptable guidelines regarding the yet unsolved issue of the media in unfettered crime reporting and the stance of the medico-legal expert towards the media.

\section{References}

1. "Sri Lanka 2015 Crime and Safety Report". www.osac.gov. N.p., 2017. Web. [cited 12 Jan. 2017].

2. James C, David M. Media and Cultural Theory. 1st ed. Oxon: Rout ledge, 2017. Web. [cited 12 Jan. 2017].

3. PublishYourArticles.net - Publish Your Articles Now. 2017 [cited 12 January 2017]. Available from:

http://www.publishyourarticles.net/eng/articles2/ an-essay-on-the-role-of-media/2481/

4. Privacy versus the Right to Know. School video news [Internet]. 2017 [cited 12 January 2017]. Available from: http://schoolvideonews.com/BroadcastJournalism/Privacy-versus-the-Right-to-Know

5. Fog A. Mass Media. 1st ed. Dordrecht: Kluwer Academic Publishers; 1999.[cited 12 January 2017]http://www.agner.org/cultsel/toc.php?e $=0,1$ ,2\#0, 
6. Lipschultz J, Hilt M. Crime and Local Television News: Dramatic, Breaking, and Live From the Scene by Jeremy H. Lipschultz, Michael L. Hilt p. 21- 23 [Internet]. 1st ed. United States: Lawrence Erlbaum Associates; 2017 [cited 12 January 2017]. Available from: https://www.amazon.com/Crime-LocalTelevision-News-Communication/dp $/ 0805$ 836217

7. Leverentz, A. "Narratives Of Crime And Criminals: How Places Socially Construct The Crime Problem". Sociological Forum 27.2 (2012): 348-371. Web. [cited 16 Mar. 2017].

8. Yanich, D. "Crime Creep: Urban and Suburban Crime on Local TV News". Journal of Urban Affairs 26.5 (2004): 535-563. Web. 16 Mar. 2017.

9. Gemeinschaftsgefühl: Community Feeling/Social Feeling/Social Interest | AdlerPedia [Internet]. Adlerpedia.org. 2017 [cited 12 January 2017]. Available from: https://www.adlerpedia .org/ concepts/15

10. If the Media Calls: A Guide for Crime Victims \& Survivors [Internet]. Canadian Resource Centre for Victims of Crime. 2017 [cited 12 January 2017]. Available from: https://crcvc.ca/publications/if-the-media-calls/

11. Krages B. Legal Handbook for Photographers: The Rights and Liabilities of Making Images (Legal Handbook for Photographers: The Rights \& Liabilities of) Paperback - November 1, 2006 by Bert Krages (Author) [Internet]. 1st ed. Buffalo, New York: Craig Alesse; 2017 [cited 12 January 2017]. Available from: https://www.amazon.com/Legal-HandbookPhotographers-Rights-Liabilities/dp/1584281944

12. 5-year-old child strangled and sexually molested: JMO [Internet]. 2017 [cited 12 January 2017]. Available from: https://www.youtube.com/watch?v=uoRGwQ7r Osg

13. Body of Kotadeniyawa missing child found; magisterial inquest held [Internet]. 2017 [cited 12 January 2017]. Available from: https://www.youtube.com/ watch? v=3 jmf 0R huntg

14. Impulsive villagers around Seya's house 'Kondaya's house too ransacked [Internet]. 2017 [cited 12 January 2017]. Available from: https://www.youtube.com/watch?v=yzw4zZBIJ R0

15. RanjanRamanayake Speaks about Seya Sadewmini'sMurder [Internet]. 2017 [cited 12 January 2017.]available from:https://www .youtube.com/watch?v=heq5OBAjIrk\&index $=63$ \&list= PLN SVUKCikUJYc_RFIiY9 DCZK iv Z8MqEhf

16. Daeid, NN. Fifty Years of Forensic Science: A Commentary. 1st ed. John Wiley \& Sons, 2010. Print. 